\title{
21 EXPRESSION OF ADIPOCYTOKINES AT SITES OF BONE REMODELLING IN RHEUMATOID ARTHRITIS
}

G Krumbholz, ${ }^{1}$ A Lehr, ${ }^{2}$ M Rickert, ${ }^{3}$ S Rehart, ${ }^{2}$ G Schett, ${ }^{4}$ U Müller-Ladner, E Neumann ${ }^{1}$ Department of Internal Medicine and Rheumatology, Justus-LiebigUniversity Gießen, Kerckhoff-Klinik Bad Nauheim, Germany; ${ }^{2}$ Department of Orthopedics and Trauma Surgery, Markus-Hospital, Frankfurt, Germany, ${ }^{3}$ Department of Orthopedics and Orthopedic Surgery, University Hospital Gießen and Marburg, Gießen, Germany; ${ }^{4}$ Medical Clinic 3: Rheumatology and Immunology, Erlangen, Germany

10.1136/annrheumdis-2011-201237.21

Background Rheumatoid arthritis (RA) is associated with increased production of adipocytokines, which are cytokine-like mediators. Increased levels of the adipokines adiponectin and resistin in synovial fluids of RA patients as well as their activating/inhibitory effect on cells of bone remodeling (eg, osteoblasts, osteoclasts) raise the question of immunomodulatory properties of these cytokines towards bone resorption. In this study, the expression of adiponectin and resistin in joint compartments and cells at the sites of bone remodelling in RA was analysed.

Methods Bone tissue was obtained from RA patients during joint replacement surgery. Serial sections of decalcified and deparaffinised bone tissue were prepared. Immunohistochemistry was used to identify the localisation of adipokines at sites of bone remodelling in articular bone and for identification of cells expressing the adipokines adiponectin and resistin. Additionally, immunohistochemical 
staining was carried out by using antihuman ALP (alkaline phosphatase) antibodies for identifying osteoblasts and TRAP staining to identify osteoclasts. For histological overview, a Masson Trichrome staining was performed.

Results Adiponectin and resistin were detectable in all joints of RA patients at sites of bone remodelling. An expression of adiponectin and resistin by osteoblasts and osteoclasts could be observed. Both adipokines were co-localised with osteoblasts at the border of newly formed, non-mineralised bone tissue. Interestingly, a correlation of the expression intensity of resistin with the expression of ALP in osteoblasts could be observed, indicating that active osteoblasts produce increased amounts of resistin.

Conclusions The results indicate that resistin and adiponectin are expressed by osteoblasts and osteoclasts at sites of bone erosion. Therefore, these cell types are able to respond to resistin and adiponectin in bone tissue, which potentially further contribute to the differentiation and activation of these cell types.

Acknowledgement Funded by the German Research Society (SPP1468, IMMUNOBONE, NE1174/6-1). 